\title{
NOTÍCIES
}

\section{Al pare Llompart}

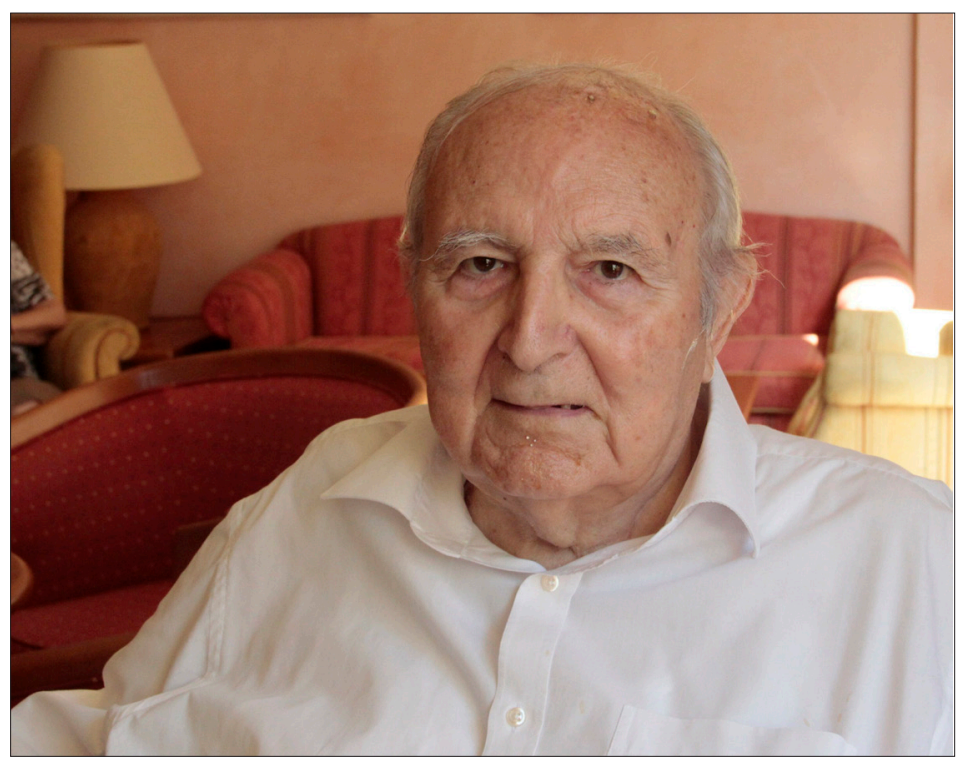

Font: Arxiu Última Hora. Joan Torres.

El doctor Gabriel Llompart Moragues (Palma, 1927-2017), per tots anomenat pare Llompart, va publicar diferents articles a Mayurqa durant les dècades dels setanta i dels vuitanta. En aquest escrit de record a una figura de gran i reconeguda talla intel-lectual recuperarem els continguts d'aquelles aportacions, les quals contribuïren a la renovació dels nostres estudis, com tota la bibliografia de l'autor.

El pare Llompart va escriure set articles per a la revista Mayurqa, un dels quals en col-laboració, una bona mostra dels interessos i metodologia de treball que el distingiren. Els cinc primers foren escrits quan la revista pertanyia a la Facultat de Filosofia i Lletres, i aquesta depenia de la Universitat de Barcelona. El curs 1979-80, data de publicació del sisè article, la Facultat s'havia incorporat a la Universitat de Palma de Mallorca, acabada de crear, i la revista passava per una nova etapa. Pel que fa al setè i darrer article, de 1989, Mayurqa era ja la revista del Departament de Ciències Històriques i Teoria de les Arts de la Universitat de les Illes Balears.

Una línia de treball se centrà en el folklore, o estudi de les tradicions, la pietat popular i la imatgeria que l'acompanya: «Devoción e iconografía popular del Nombre de Jesús en la isla de Mallorca» (1972, v. 7, 53-65); «Sa Jaia Corema, Sa Jaia Serrada: un apunte de iconografía popular mallorquina» (1976, v. 15, 189-197); i «El patrocinio de S. José en Mallorca y su talante folklórico e iconográfico» (1979-80, v. 19, 323-336).

En el primer, es traça la història de la devoció al Nom de Jesús com una de les més arrelades a l'illa de Mallorca, i vincula aquesta devoció amb expressions populars ben vigents a dia d'avui, una mostra de la capacitat del pare Llompart per acostar l'estudi del passat al món actual. En el relat, l'autor s'ocupa de tres grans vessants del tema: història de la devoció durant els darrers segles de l'edat mitjana i l'edat 
moderna; panoràmica sobre l'ús del monograma de Jesús en la litúrgia, els repertoris decoratius populars i els gravats; fonts espirituals de la devoció i difusió a l'illa de Mallorca.

El seu article sobre la Jaia Corema, la Jaia Serrada, recull la presència d'aquesta figura en el camp del gravat català i de la tradició oral des de final del segle XVIII. Això motiva una detinguda descripció iconogràfica i iconològica de la imatge, com també del cerimonial popular que la festejava al temps de Quaresma. Especial importància té l'aparell gràfic que s'inclou com a apèndix, atès que abasta diferents manifestacions artístiques i obres mallorquines, catalanes, hispàniques i italianes, una aportació que transcendeix l'esfera local i que li permet plantejar la possible creació d'un model propi per a la imatge mallorquina.

Finalment, dins aquesta línia d'estudi incloem un breu article sobre la devoció a sant Josep. Per traçar la seva història a Mallorca des de final del segle XVI al segle XIX, l'autor recorre a la documentació concernent als patronatges gremials a la ciutat de Mallorca, a les notícies històriques sobre les devocions i formació de confraries a les parròquies de la Part Forana, com també a l'ús de la imatge del sant en la iconografia religiosa i la tradició oral.

Altres tres articles, escrits durant la dècada dels setanta, tracten de temes específics de la Història de l'Art a les Illes: «La orfebrería mallorquina en torno a 1400» (1974, v. 12, 87-123); juntament amb Mathieu Hériard Dubreuil, «El Tríptico del Varón de Dolores del convento de Santa Clara de Mallorca» (1975, v. 13, 211-215); i «Dos puntualizaciones definitivas sobre el retablo manierista de Sineu» (1976, v. 16, 265-276).

Els estudis sobre argenteria mallorquina que s'han publicat des de la dècada dels noranta es fan ampli ressò del valor de la primera publicació del pare Llompart dedicada al tema. Es tracta d'un estudi de conjunt, centrat en un període divers del que havia treballat abans Marcel Durliat, que posà les bases documentals, tipològiques i iconogràfiques per als futurs estudis sobre argenters i obres dels darrers anys del segle XIV i primers del següent. Aquesta aportació parteix de les dues figures i obres fonamentals del període i de tot el segle XV: Antoni Oliva, artífex de la creu processional de la parroquial de Porreres; i Francesc Martí, argenter de la custòdia de la catedral d'Eivissa. En ambdós casos, el pare Llompart traçà les biografies dels autors, i inclogué dades sobre les trajectòries artístiques, l'entorn social, l'activitat econòmica i de treball als respectius tallers. En relació amb les obres, són objecte d'una minuciosa descripció, que abasta tots els aspectes significatius, que li permet la contextualització historicoartística i, en el cas de la creu de Porreres, li permet d'oferir una proposta sobre el programa iconogràfic. També s'ha de destacar el relat sobre el significat d'aquestes obres en l'esfera de la pietat popular, una perspectiva que interessà especialment al pare Llompart com a historiador de l'art. Com que és un estudi basat en la documentació d'arxiu, l'autor aportà els contractes de les dues obres estudiades, la qual cosa li permeté fixar autories i datacions, com també notícies sobre altres argenters de l'època amb obra desapareguda. Com fou tònica habitual en els seus escrits, un generós apèndix recull la transcripció d'aquests i altres documents inèdits que utilitzà en la investigació.

L'any 1975 col-laborà amb el professor Dubreuil, conegut investigador especialitzat en pintura gòtica valenciana, en un article dedicat a un tríptic de principi del segle XV que representa el baró de Dolors, amb les imatges de l'Anunciació a les ales. Obra coneguda, però que llavors no gaudia d'estudis exhaustius, els autors se centraren en la filiació estilística, amb especial atenció als esquemes compositius i als motius iconogràfics, els quals els conduïren a l'escola valenciana del gòtic internacional. Aquesta hipòtesi seria corroborada anys després per Llompart en una segona publicació, en aquest cas individual, on pogué precisar la identitat del promotor i, per tant, la datació aproximada de la peça.

El retaule de la parroquial de Sineu, realitzat en gran part a final del segle XVI, seria objecte d'un nou estudi, atès que, com el títol de l'article explicita, necessitava d'aclariments. L'autor fa una minuciosa descripció de l'obra, dispersa en diversos indrets des de final del segle XIX, i l'explica com a resultat de la intervenció de dos artífexs en períodes diferents, Gabriel Mòger i Gaspar Janer, a inicis i finals del segle, 
respectivament. El treball sobre una obra concreta serví a l'autor per a oferir sengles monografies dels escultors, en les quals s'ampliaren els catàlegs i el coneixement de les trajectòries. Quedà així traçat, per a la historiografia posterior, el perfil del darrer gran escultor del gòtic mallorquí, Gabriel Mòger, conegut especialment per les imatges marianes, com és el cas de la Mare de Déu Sagrari de Sineu. I es fa la primera monografia sobre Janer, important autor de retaules a Mallorca i València.

El número de la revista Mayurqa de 1989 estigué dedicat al doctor Álvaro Santamaría, catedràtic d'Història Medieval a la nostra universitat. El pare Llompart contribuí a aquest llibre homenatge amb una incursió en la història econòmica local durant l'edat mitjana. «La nómina municipal de la Ciudad de Mallorca en 1374» (1989, v. 22, 367-372) és un article necessàriament breu, tot i que tracta d'un aspecte poc conegut i, com sempre, sobre documentació inèdita o poc treballada fins al moment.

Un dels homenatges que va rebre el pare Llompart, amb ocasió del seu vuitanta aniversari, consistí en una miscel-lània d'articles coordinada i editada pels Amics del Museu de Mallorca («Els amics al pare Llompart. Miscel-lània in honorem», Palma, 2009). Capítols sobre iconografia, litúrgia, argenteria, recopilacions documentals sobre artesans i oficis artístics, patrimoni cultural, arts decoratives, història religiosa, social i econòmica, urbanisme, art funerari, història de la pintura i de l'escultura, tècniques artístiques, història de la festa i de les tradicions populars durant les èpoques medieval i moderna, com també sobre arqueologia i història antiga, són mostra de l'ampli ventall i perfil dels investigadors que tingueren relació personal o professional amb ell. Sobretot, emperò, de l'amplitud de mires que va distingir l'homenatjat en els seus treballs de recerca, quant a temes, objectius i metodologies de treball. Les 361 entrades bibliogràfiques recollides a l'apèndix final d'aquesta publicació parlen per si mateixes.

Les publicacions del doctor Gabriel Llompart s'iniciaren el 1945, i des de llavors continuà investigant i divulgant els resultats assolits fins quasi al final de la seva vida. Teòleg, historiador, historiador de l'art i folklorista, les seves contribucions són destacables en tots aquests àmbits. Això no obstant, per acabar aquest text, s'ha de fer especial menció a la seva tesi doctoral, La pintura medieval mallorquina, presentada a la Universitat de Barcelona el 1974, per l'amplitud i importància de l'obra, com ha estat reconeguda en l'àmbit català i hispànic, també en contextos europeus. Publicada en quatre volums entre 1978 i 1980, La pintura medieval mallorquina. Su entorno cultural y su iconografía abasta els camps significatius per a l'estudi: aporta un volum de documentació relativa a peces i artistes, i un segon per al catàleg de peces, es treballen els aspectes iconogràfics, tracta sobre els aspectes de producció de les arts del color, i també utilitza les fonts escrites i pictòriques per al coneixement de la ciutat i la casa medieval. Per tant, és una obra molt àmplia també en el sistema de treball, en el qual s'uneix la recerca documental amb l'enfocament iconogràfic, la preocupació sociològica i el que es coneix com a història de les mentalitats o de la vida quotidiana.

Els escrits del pare Llompart són el punt de partida —alguns també encara d'arribada - per al coneixement de molts i variats aspectes de la història mallorquina. Són obres de referència per a generacions d'historiadors.

Tina Sabater

Universitat de les Illes Balears 